the lid became rapidly swollen, with at first little discharge, the lids sticking torether; and at the same time a great many "pimples" made their appearance on the face. Last Saturday (Oct. 27th)-i. c., two days since-the child seemed ill, feverish, and cross, and was attacked by a severe cough. On one of the shoulders, near the root of the neck, appeared four umbilicated bullulæ, of about the size of split peas, slightly confluent, with two others quite isolated. They have the aspect of scalds. There is a great "running" at the nose. The eye is inflamed, and discharging pus. The external part of the ear (the pirina) is sore; and on the inner aspect is one pustular spot, of about the size of those on the back, depressed in the centre, looking just like some examples of variola. With cod-liver oil and zinc ointment, the child got well; the later progress of the case showing the peculiar crusts of "porrigo".

This was a good example of so-called bastard vaccinia-a transition stage, it would appear, between vaccinia and impetigo contagiosa. The changes as to time and character were different from those of variola or vaccinia; and yet, in external aspect, one could not fail to see some relation. The disease lasted about a month. I have never seen the exact like of the case before, and at first it puzzled.

CASE v. E. D., aged 2 years, seen September 3rd, 1863, was vaccinated four months ago. The operation succeeded admirably, and the sores left healed up perfectly. The child is in good health, and there is no evidence of scrofula in the family history. It appears that an elder brother was laid up with smallpox, and this child was vaccinated in consequence. There is a "porriginous" spot on the left arm, at the seat of vaccination; also on the right arm, between the buttocks, on the head, and on the right thigh. There are on the left arm six circular spots in the six separate punctured (vaccinated) places; they are dull red, quasi-squamous, depressed below the surrounding integuments, feel harsh; their colour goes by pressure. There is no copper stain ; and immediately joining is a yellow crusted spot. Just above the elbow is a circular patch, made up of aggregated spots, and freely crusted, of about the size of a shilling. On the forearm are two more; and above the wrist another place, of the size of a sixpence. Between the buttocks, the two spots are about as large as a shilling, and possess a raised thickened edge, with depressed centres, and an ulcerating surface. Codliver oil, administered internally, was the sole remedy used.

The above five cases are quoted as illustrations rather of the more uncommon instances and aspects of the disease.

15, Old Cavendish Street, w.

\section{TARTARISED ANTIMONY AS A REMEDY IN STRUMOUS OPHTHALMIA.}

By Edwin Chesshire, F.R.C.S., Senior Surgeon to the Birmingham and Midland Eye Hospital.

I HAVE so frequently prescribed tartar emetic, generally in combination with opium (but often alone), in strumous ophthalmia, as well as in acute corneal and conjunctival inflammations, and with such marked success, that I have no hesitation in suggesting to my professional brethren a more extensive use of the remedy in the treatment of those obstinate, and frequently protracted, affections of the eye.

In cases of strumous ophthalmia, where there was excessive photophobia, I have found the internal administration of tartarised antimony, in doses varying from one-twentieth to one-twelfth of a grain, accord- ing to the age of the patient, to be attended with the most decided benefit; and its efficacy has been singularly marked, where quinine, steel, arsenic, and cod-liver oil, had each, in its turn, been tried and failed. No remedy that I know of so completely or so permanently removes the photophobia, which is such a distressing symptom in strumous affections of the eye.

In phlyctenular ophthalmia, and in vascular cornea or pannus, uncomplicated with a granular condition of the palpebral conjunctiva, or with inversion of the cilia (trichiasis), a continued course of tartar emetic, in small doses, arrests the progress of the affection most effectually, and with it may be combined the early use of local stimulants, a combination which may be continued, if necessary, for a lengthened period without injury to the general health; in fact, the patients who have taken tartarised antimony under my care, both at the Eye Hospital and in private practice (and I have prescribed it very extensively), have almost invariably told me how much stronger and more energetic they felt during the time they were taking the remedy. I am aware it has long been the practice of ophthalmologists to administer a single emetic dose of tartarised antimony, as a beginning to the treatment of strumous ophthalmia; and that it has occasionally been given in combination with bark and quinine; but it does not appear to have been resorted to as a remedy, per $s e$, for the cure of strumous affections of the eye. It is quite true, in the case of the little strumous patients, while under treatment, that they were usually placed on milk diet; and, when the photophobia was severe, attention was paid to the exclusion of light, which would probably assist in promoting a favourable result; but the same diet was generally resorted to, and the same care to exclude light was taken, when the treatment had consisted of cod-liver oil, quinine, etc., and yet often with an unsatisfactory result.

Unlicensed Lunatic Asylums. Mrs. Sophia Leander, of Zion House, Turnham Green, was charged on Monday, with unlawfully receiving into the house occupied by her more than two lunatics, such house not being an asylum or hospital registered under the provision of the Act of Parliament. The magistrate sent the case for trial at the Sessions; $\mathbf{M r}$. Leander giving bail for the appearance of his wife. Dr. Christie, superintendent of the Hackney Lunatic Asylum, stated that he had inspected Zion House, in company with Mr. Luttridge, one of the Lunacy Commissioners. There were about eighty inmates. $\mathrm{He}$ examined four or five of the patients, and found them to be persons of unsound mind. The premises were certainly not proper for the accommodation of so many persons in this condition.

Philadelphia Military Hospitals are models of cleanliness and good order. From all quarters they extort praise and admiration. We have at present the South St. Hospital, an old silk factory, with about 250 beds; the Christian Street, with a like number; the Filbert Street, about 400 ; the West Philadelphia or Satterlee, accommodating 2,500 patients ; the Chestnut Hill, or Mower, about 3,000 ; the Turner's Lane, the Nicetown and the Germantown Hospitals, each of much less proportions. Four of these were built as army hospitals, and are models of the kind, being splendidly ventilated, and supplied with every means to restore the health of the sick or wounded patriots who may be brought under their shelter. In addition, we have an officers' hospital at Camac's Woods, where officers are furnished with hospital attendance at a reasonable rate. (American Medical Times.) 